\title{
Disparities in the Use of Internet and Telephone Medication Refills among Linguistically Diverse Patients
}

\author{
Gerardo Moreno, MD, MSHS , Elizabeth H. Lin, MD, MPH², Eva Chang, MPH, $P \mathrm{D}^{2}$, \\ Ron L. Johnson, $\mathrm{MA}^{2}$, Heidi Berthoud, MPH ${ }^{2}$, Cam C. Solomon, PhD ${ }^{3}$, and Leo S. Morales, MD, PhD 2,4 \\ 'UCLA Department of Family Medicine, David Geffen School of Medicine at UCLA, Los Angeles, CA, USA; ${ }^{2}$ Group Health Research Institute, Seattle, \\ WA, USA; ${ }^{3}$ School of Social Work, University of Washington, Seattle, WA, USA; ${ }^{4}$ Center for Health Equity, Diversity and Inclusion, School of Medicine, \\ University of Washington School Medicine, Seattle, WA, USA.
}

BACKGROUND: Health systems are increasingly implementing remote telephone and Internet refill systems to enhance patient access to medication refills. Remote refill systems may provide an effective approach for improving medication non-adherence, but more research is needed among patients with limited English proficiency with poor access to remote refill systems.

OBJECTIVE: To compare the use of remote medication refill systems among limited-English-proficiency (LEP) and English-proficient (EP) patients with chronic conditions.

METHODS: Cross-sectional survey in six languages/ dialects (English, Cantonese, Mandarin, Korean, Vietnamese, and Spanish) of 509 adults with diabetes, hypertension, or hyperlipidemia. Primary study outcomes were self-reported use of 1) Internet refills, 2) telephone refills, and 3) any remote refill system. LEP was measured by patient self-identification of a primary language other than English and a claims record of use of an interpreter. Other measures were age, gender, education, years in the U.S., insurance, health status, chronic conditions, and number of prescribed medications. Analyses included multivariable logistic regression weighted for survey non-response.

RESULTS: Overall, 33.1 \% of patients refilled their medications by telephone and $31.6 \%$ by Internet. Among LEP patients ( $n=328$ ), $31.5 \%$ refilled by telephone and $21.2 \%$ by Internet, compared with $36.7 \%$ by telephone and $52.7 \%$ by Internet among $\mathrm{EP}$ patients $(n=181)$. Internet refill by language groups were as follows: English (52.7\%), Cantonese (34.9\%), Mandarin (17.4\%), Korean (16.7\%), Vietnamese $(24.4 \%)$, and Spanish (12.6\%). Compared to EP patients, LEP patients had lower use of any remote refill system (adjusted odds ratio [AOR] 0.18; $p<0.001)$,

CONCLUSIONS: LEP patients are significantly less likely than EP patients to use any remote medication refill system. Increased reliance on current systems for remote medication refills may increase disparities in health outcomes affecting LEP patients with poor access to telephone and Internet medication refills.

Received March 17, 2015

Revised July 20, 2015

Accepted August 11, 2015

Published online August 27, 2015
KEY WORDS: language barriers; minority health; survey research; disparities; adherence.

J Gen Intern Med 31(3):282-8

DOI: $10.1007 / \mathrm{s} 11606-015-3500-6$

(C) Society of General Internal Medicine 2015

\section{INTRODUCTION}

The availability of websites that allow patients access to their personal electronic medical records and secure communication with their physician may provide patients with an important option for refilling their medications. Internet-based shared medical records (SMR) can increase access to pharmacy services for patients with the necessary skills, services (i.e., Internet access), and technologies (i.e., computer) to use them. Although expanding nationally, the use of Internet-based SMRs with prescription medication refill capability is relatively new in many health systems. ${ }^{1}$ The use of SMRs with online medication refill function has the potential to improve medication adherence, which is a common problem, with serious health, safety, and cost implications. ${ }^{2}$

Research among English-speaking populations shows that patients are interested in the integrated functionality of an online SMR with medication management capabilities and specifically welcome the convenience to request medication refills. ${ }^{3}$ However, research on the use of refill functions of SMRs is scarce among patients whose primary language is not English. Patients with limited English proficiency and chronic conditions are at increased risk of medication nonadherence $^{4,5}$ and receive lower-quality care than patients who are proficient in English. ${ }^{6-8}$ One study suggested that patient use of an online portal with refill function increased adherence to statin medications for those with diabetes receiving care in an integrated health system., ${ }^{9,10}$

Studies also report that low education, income, and Internet access are associated with lower online use of an SMR, though socioeconomic status (SES) alone does not account for lower SMR use by racial-ethnic minorities. ${ }^{11}$ African Americans and Latinos are less likely to use an online SMR system that has options to request medication refills. ${ }^{12-14}$

In view of the lack of reliable data on patient language use in most health care systems, and the enormous challenges of 
conducting cross-cultural and multi-lingual research, to our knowledge, there are no studies examining the use of the medication refill functionality of SMRs by linguistically diverse populations. This study addresses this gap by investigating the use of Internet and telephone medication refill systems integrated within an SMR among an ethnically diverse sample of insured patients with chronic illnesses, and investigates differences in use between patients with limited English proficiency (LEP) and English-proficient (EP) patients.

\section{METHODS}

\section{Setting and Data}

This study was conducted within Group Health Cooperative, a mixed-model, not-for-profit, integrated group practice healthcare system in the state of Washington. Group Health has an electronic medical record (EMR) and integrated online shared medical records (SMR) for patients in their integrated group practice. Available since 2003, the online SMR is available in English and is used by more than half of Group Health patients. ${ }^{1}$ As described elsewhere, the SMR site allows patients to (1) exchange secure electronic messages with their healthcare team, (2) view portions of their electronic health record, including medications, (3) obtain medication refills with shipping to their homes, (4) obtain after-visit summaries, and (5) schedule office appointments. ${ }^{1}$ Group Health also has a remote telephone system available in English, and allows patients to request medication refills. The remote refill systems are not available in other languages. This study was approved by the institutional review boards at Group Health Research Institute and UCLA.

The study uses four sources of data: health plan enrollment data that includes some demographics (age and gender), inpatient and outpatient claims data that includes interpreter utilization data, electronic medical records, and telephone survey data. Group Health maintains records of all encounters where an interpreter was used, and each encounter-level record includes date, language, service location, and duration.

\section{Study Design and Sample}

We conducted a cross-sectional telephone survey in the six most common languages/dialects among patients at Group Health: English, Cantonese, Mandarin, Korean, Vietnamese, and Spanish. The survey study inclusion criteria were (1) age 18 years or older, (2) continuous enrollment in Group Health integrated group practice 6 months prior to the beginning of the survey, (3) diagnosis of one of the three chronic conditions-hypertension, hyperlipidemia, and/or diabetes - as defined by two outpatient ICD-9 diagnoses or one inpatient diagnosis, (4) at least one medical visit (not urgent care or emergency) within the health system during the last 6 months, and (5) a primary language of English, Cantonese, Mandarin, Korean, Vietnamese, or Spanish. For patients whose primary language was not English, an additional inclusion criterion was the use of an interpreter during at least one clinical visit between 2005 and 2012. Patient exclusion criteria were diagnosis of dementia or Alzheimer's disease; admission to hospice, hospital, or skilled nursing facility in last 12 months; diagnosis of end-stage renal disease (stage 5) or receiving dialysis; pregnancy within the prior year; or placement on the health system's "no contact" list. All LEP patients satisfying the inclusion and exclusion criteria were included. English-speaking patients were identified by inclusion and exclusion criteria, matched for age, gender, and chronic conditions, and randomly selected.

\section{Survey Development}

The 96-item survey was pre-tested with English-speaking volunteers and forward- and back-translated by a vendor into each language (Spanish, Korean, Chinese, and Vietnamese) by certified translators. The surveys underwent a review process with reconciliation calls that involved bilingual members of our team, the vendor, and translators. The reconciliation process focused line-by-line on the survey, ensuring each item was properly translated.

\section{Data Collection}

Telephone survey administration was conducted by a vendor in California between September 2013 and January 2014. Potential participants received language-appropriate materials and a one-dollar bill via mail for consent in advance of receiving a call by a trained interviewer who spoke the respondent's language. Interviewers attempted to contact 1490 patients (493 EP and 997 LEP), making up to 25 calls per patient at different times and days of the week. Roughly twice as many LEP as EP patients were sampled, with the goal of adequate representation by each language group included in the study. Ultimately, 509 patients completed the survey and received a $\$ 10$ gift card via mail. The overall response rate was $35.5 \%(n=509 ; 34.0 \% \mathrm{EP}, n=328$; and $37.4 \%$ LEP, $n=181)$. The majority of non-response was due to refusal or maximum call attempts reached.

\section{Measures}

Primary outcomes were use of 1) Internet refill system, 2) telephone refill system, and 3) any remote refill system (Internet or telephone). Patients were provided with a brief description of the Internet refill system and then asked, "Have you used the health systems Internet site to refill any medications in the last 12 months?" (response options: yes, no, or don't know). A similar question was asked about use of the automated telephone medication refill system. One dichotomous variable was created to indicate use of each refill system. Respondents who answered "don't know" ( $n=14$ for Internet and 9 for telephone) were categorized as "no" or not using the remote refill systems. A third dichotomous variable was 
created to indicate whether patients used either the telephone or Internet refill systems. A second question was used to ascertain the frequency of use of the remote refill systems among those who answered "yes" to using one or both in the past 12 months. Patients who reported using the Internet refill system were asked, "How frequently have you used this system to refill your medication in the last 12 months" (response options: sometimes, usually, or always). A similar question was asked to those who reported use of the telephone refill system.

The primary predictor variable was LEP status as measured by patient self-identification of a primary language other than English and a claims record of use of an interpreter. Other measures included in the survey were language/dialect (English, Cantonese, Mandarin, Korean, Vietnamese, or Spanish), race-ethnicity, age, gender, education (high school or less, trade school, or university/college), household income, and health status. Self-reported health status was recoded as excellent/very good, good, or fair/poor. Patients born outside the U.S. $(n=328)$ were asked about the number of years living in the US. The survey responses were merged with EMR data to determine the number of prescribed medications, presence of chronic conditions (diabetes mellitus, hypertension, and/or hyperlipidemia), and insurance type. Missing responses were less than $1 \%$ for all variables except the income question, where $4.9 \%$ refused to answer and $8.6 \%$ answered "don't know."

\section{Analysis}

STATA version 12.0 (StataCorp LP, College Station, TX, USA) statistical software was used for all analyses, and a $p$ value of $<0.05$ was used to determine statistical significance. We calculated inverse probability weights (IPW) to account for differential survey response from study participants by age group and language. We modeled response as the dependent variable in a logistic regression model, and included age and language as independent predictors. The IPW was then calculated as $1 / \operatorname{Prob}(Y \mid X i)$, where $Y$ is a dichotomous variable, $X_{1}$ is patient's age ( 18 to $44,45-64$, and 65 or greater) and $X_{2}$ is the patient's language, resulting in 15 IPWs ( 3 age categories by 5 languages), which we used to weight all respondents in our analyses.

We examined univariate summary statistics to determine distributions for all variables using the survey weights. We then performed bivariate analyses for each of the three outcome variables (use of Internet refill system, use of telephone refills, and any remote refill system) by all patient demographic characteristics and health-related measures. Bivariate associations were assessed for statistical significance using $\chi^{2}$ tests for categorical variables and one-way analysis of variance for continuous variables.

We estimated logistic regression models, one for each outcome variable, to estimate the association between English proficiency and each outcome, adjusting for age, gender, education, and self-reported health status. We used the literature and prior studies to determine the most parsimonious models given sample size considerations. ${ }^{4,5}$ We conducted post hoc analyses to determine whether including household income or the number of medications attenuated the effect size or changed the direction of the association with each outcome measure.

\section{RESULTS}

Table 1 reports weighted patient demographics and clinical characteristics for all survey respondents stratified by LEP status. EP patients were significantly older, single or divorced, had higher household income, were more educated, reported better health status, and had more concurrent medications, compared to LEP patients.

Among all survey respondents, both EP and LEP $(n=509)$, $34 \%$ of patients reported using the telephone refill system and $32 \%$ using the Internet to refill medications (data not shown). Among all patients who reported using the Internet to refill medications $(n=160), 80 \%$ used it usually or always, and $19 \%$ used it only sometimes. Among all patients who reported using the telephone to refill medications ( $n=177), 75 \%$ used it usually or always, and $25 \%$ used it sometimes.

As illustrated in Fig. 1, the frequency of use of Internet and telephone refill systems varied by LEP status. Half of EP patients (53\%) used the Internet refill system, compared to $21 \%$ of LEP patients; $83 \%$ of EP patients used either the telephone or Internet refill system, compared to $46 \%$ of LEP patients; and similar proportions of EP (37\%) and LEP (31\%) used the telephone refill system (Fig. 1).

Table 2 shows use of the telephone and Internet refill systems by various unadjusted patient characteristics. Women were more likely to use the telephone or any remote refill system, but there were no significant gender differences for use of Internet refills. Those with higher income or higher education levels were more likely to use Internet refills, but not telephone refills. Use of any remote refill system was greater among patients with higher education or income. The proportion of patients by language group who used the Internet refill system was: English (53\%), Cantonese (35\%), Mandarin $(17 \%)$, Korean $(17 \%)$, Vietnamese $(24 \%)$, and Spanish $(13 \%)$. The proportion of patients by language group who used the telephone refill system was: English (37\%), Cantonese $(19 \%)$, Mandarin (17\%), Korean (48\%), Vietnamese (26\%), and Spanish (36\%). Those with fewer years in the U.S. were less likely to use the telephone to refill medications. Patients with Medicare/Medicaid insurance or fair/poor health status were less likely to use the Internet to refill medications. The use of Internet, telephone, and any remote refill system was greater among patients with a higher mean number of prescribed medications.

Table 3 shows results from three logistic regression models, examining (1) use of Internet refills, (2) use of telephone 
Table 1 Weighted percentages and means for patient characteristics $(n=509)$ by limited English proficiency (LEP) status

\begin{tabular}{|c|c|c|c|c|}
\hline \multirow[t]{2}{*}{$\overline{\text { Characteristic }}$} & \multirow{2}{*}{$\begin{array}{l}\text { All patients } n=509 \\
\%\end{array}$} & \multirow{2}{*}{$\begin{array}{l}\text { EP patients } n=181 \\
\%\end{array}$} & \multirow{2}{*}{$\begin{array}{l}\text { LEP patients } n=328 \\
\%\end{array}$} & \multirow[t]{2}{*}{$\overline{P \text { value }^{\dagger}}$} \\
\hline & & & & \\
\hline Age, mean years $(\mathrm{SE})(n=509)$ & $63.9(0.49)$ & $66.9(0.89)$ & $62.5(0.57)$ & $<0.001$ \\
\hline Female $(n=509)$ & 62.6 & 60.6 & 63.6 & 0.50 \\
\hline \multicolumn{5}{|l|}{ Marital status $(n=506)$} \\
\hline Single or never married & 4.8 & 7.7 & 3.3 & \multirow[t]{3}{*}{0.02} \\
\hline Married or living with a partner & 72.3 & 64.7 & 76.0 & \\
\hline Divorced, separated or widowed & 23.0 & 27.6 & 20.7 & \\
\hline \multicolumn{5}{|l|}{ Household income $(n=440)$} \\
\hline$<\$ 25,000$ & 25.6 & 6.9 & 35.7 & \multirow[t]{4}{*}{$<0.001$} \\
\hline$\$ 25,000-\$ 49,999$ & 32.9 & 31.0 & 33.9 & \\
\hline$\$ 50,000-\$ 74,999$ & 23.0 & 27.6 & 20.5 & \\
\hline$\geq \$ 75,00-\$ 99,000$ & 18.6 & 34.5 & 9.9 & \\
\hline \multicolumn{5}{|l|}{ Education completed $(n=501)$} \\
\hline High school or less & 54.6 & 22.3 & 71.0 & \multirow[t]{3}{*}{$<0.001$} \\
\hline Trade school & 7.9 & 7.2 & 8.1 & \\
\hline University/college & 37.5 & 70.1 & 20.9 & \\
\hline \multicolumn{5}{|l|}{ Language* $(n=509)$} \\
\hline English & 33.2 & 100.0 & - & \multirow[t]{6}{*}{$<0.001$} \\
\hline Cantonese & 10.4 & - & 15.5 & \\
\hline Mandarin & 7.4 & - & 11.1 & \\
\hline Korean & 15.9 & - & 23.9 & \\
\hline Vietnamese & 20.2 & - & 30.2 & \\
\hline Spanish & 12.8 & _- & 19.2 & \\
\hline \multicolumn{5}{|l|}{ Race-ethnicity ${ }^{\star}(n=509)$} \\
\hline White & 31.8 & 92.8 & 1.5 & \multirow[t]{7}{*}{$<0.001$} \\
\hline Black & 1.1 & 2.4 & 0.4 & \\
\hline Chinese & 18.8 & 1.8 & 27.3 & \\
\hline Korean & 16.2 & 0.0 & 24.2 & \\
\hline Vietnamese & 18.7 & 0.0 & 28.0 & \\
\hline Latino & 11.2 & 1.2 & 16.1 & \\
\hline Other & 2.3 & 1.8 & 2.5 & \\
\hline \multicolumn{5}{|l|}{ Years in the U.S. $(n=338)$} \\
\hline$<1-10$ & 6.1 & 0.0 & 6.3 & \multirow[t]{3}{*}{0.35} \\
\hline $11-15$ & 8.2 & 0.0 & 8.5 & \\
\hline 16 or more & 85.8 & 100.0 & 85.2 & \\
\hline Medicare/Medicaid ${ }^{\star}(n=506)$ & 24.9 & 27.8 & 23.5 & 0.27 \\
\hline \multicolumn{5}{|l|}{ Health status $(n=506)$} \\
\hline Excellent/very good & 25.9 & 48.4 & 14.7 & \multirow[t]{3}{*}{$<0.001$} \\
\hline Good & 36.6 & 37.8 & 36.0 & \\
\hline Fair/poor & 37.5 & 13.8 & 49.3 & \\
\hline \multicolumn{5}{|l|}{ Chronic conditions $^{*}(n=509)$} \\
\hline Diabetes mellitus & 36.8 & 30.0 & 40.1 & 0.03 \\
\hline Hypertension & 72.9 & 76.5 & 71.1 & 0.20 \\
\hline Dyslipidemia & 66.9 & 69.9 & 65.0 & 0.27 \\
\hline Number of prescribed medications, ${ }^{\star}$ mean (SE) $(n=509)$ & $6.0(0.20)$ & $7.2(0.36)$ & $5.4(0.23)$ & $<0.001$ \\
\hline
\end{tabular}

Notes: All percentages are weighted for age and language with inverse probability weights to account for differences in survey response. Column percentages presented. $E P=$ English-proficient; $L E P=$ limited English proficiency; $S E=$ standard error

* Survey administration language

† compares LEP group with EP group

$\neq$ abstracted from electronic medical record claims data

refills, and (3) use of any remote refill system. In model 1, LEP patients had lower odds of using the Internet to refill medication compared to EP patients (adjusted odds ratios [AOR] $0.27 ; 95 \%$ confidence intervals [CI] $0.17-0.45 ; p<0.001$ ); and high school or less education was associated with less use of Internet refills compared with university or college education (AOR 0.50; $95 \%$ CI $0.31-0.81 ; p<0.01$ ). In model 2, LEP status was not significantly associated with the use of telephone refills. Women had higher odds of using the telephone to refill medications than men (AOR 1.78; $95 \%$ CI 1.18-2.70; $<<0.01$ ). In model 3 , LEP patients had lower odds (AOR 0.18; $95 \%$ CI $0.11-0.31 ; p<0.001)$ of using any remote refill system compared to EP patients.
In results from post hoc sensitivity analysis (data not shown), the addition of household income and number of medications to the models did not change the results reported in Table 3.

\section{DISCUSSION}

In this study we found substantial variation in the use of telephone and Internet medication refill systems among a linguistically diverse group of adults. Among LEP patients, $46 \%$ used any remote refill system (Internet or telephone) to fill medications, compared with $83 \%$ of EP patients. Patients with LEP and EP were approximately equally likely to refill 


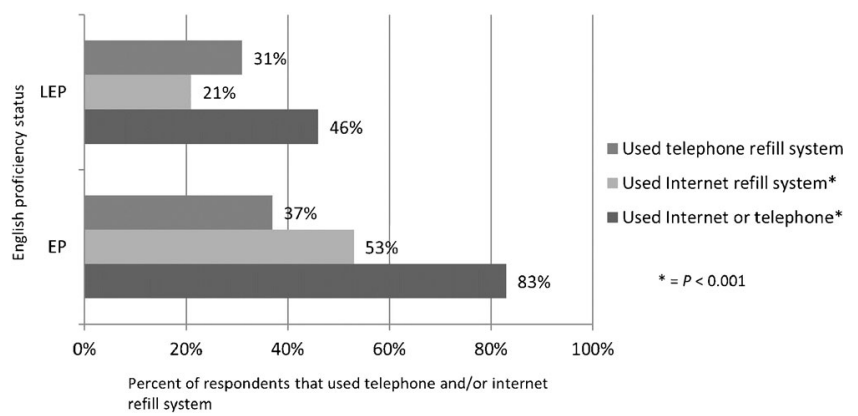

Fig. 1 Unadjusted weighted proportions of limited-English-proficiency (LEP) and English-proficient (EP) patients who reported use of Internet and/or telephone medication refill systems

medications by phone, but LEP patients were much less likely to refill by Internet. Overall, patients with LEP were much less likely than patients with EP to use either phone or Internet.

The results have important implications for health systems serving linguistically diverse populations. Optimization and tailoring the language of online SMRs with medication refill functions and automated telephone systems for linguistically diverse patients is an important area for future research and development. ${ }^{15}$

Clinically, the results are relevant to LEP patients with chronic conditions, polypharmacy, and at high risk for medication non-adherence. Other research suggests that patients

Table 2 Unadjusted weighted percentages and means of patient characteristics for use of Internet and/or telephone refill systems $(n=509)$

\begin{tabular}{|c|c|c|c|c|c|c|}
\hline \multirow[t]{2}{*}{ Characteristic } & \multicolumn{2}{|c|}{$\begin{array}{l}\text { Used Internet refills } \\
n=160\end{array}$} & \multicolumn{2}{|c|}{$\begin{array}{l}\text { Used telephone refills } \\
n=177\end{array}$} & \multicolumn{2}{|c|}{$\begin{array}{l}\text { Used Internet or } \\
\text { telephone } n=305\end{array}$} \\
\hline & $\%$ & p-value & $\%$ & p-value & $\%$ & p-value \\
\hline Age, mean years (SE) $(n=509)$ & $62.9(0.80)$ & 0.14 & $66.2(0.81)$ & $<0.001$ & $64.5(0.61)$ & 0.18 \\
\hline \multicolumn{7}{|l|}{ Gender $(n=509)$} \\
\hline Male & 31.5 & \multirow[t]{2}{*}{0.97} & 26.2 & \multirow[t]{2}{*}{0.01} & 52.6 & \multirow[t]{2}{*}{0.04} \\
\hline Female & 31.7 & & 37.2 & & 62.3 & \\
\hline \multicolumn{7}{|l|}{ Marital status $(n=506)$} \\
\hline Single or never married & 36.0 & \multirow{3}{*}{0.87} & 35.0 & \multirow[t]{3}{*}{0.68} & 65.5 & \multirow[t]{3}{*}{0.73} \\
\hline Married or living with a partner & 31.7 & & 32.0 & & 57.9 & \\
\hline Divorced, separated or widowed & 30.5 & & 36.3 & & 60.3 & \\
\hline \multicolumn{7}{|l|}{ Household income $(n=440)$} \\
\hline$<\$ 25,000$ & 17.5 & \multirow[t]{4}{*}{$<0.001$} & 29.7 & \multirow[t]{4}{*}{0.67} & 42.3 & \multirow[t]{4}{*}{$<0.001$} \\
\hline$\$ 25,000-\$ 49,999$ & 25.0 & & 33.8 & & 56.1 & \\
\hline$\$ 50,000-\$ 74,999$ & 45.9 & & 30.6 & & 68.4 & \\
\hline$\geq \$ 75,000$ & 53.9 & & 37.4 & & 81.4 & \\
\hline \multicolumn{7}{|l|}{ Education completed $(n=501)$} \\
\hline High school or less & 21.6 & \multirow[t]{3}{*}{$<0.001$} & 33.8 & \multirow[t]{3}{*}{0.52} & 50.6 & \multirow[t]{3}{*}{$<0.001$} \\
\hline Trade school & 35.2 & & 25.4 & & 53.9 & \\
\hline University/college & 45.7 & & 34.8 & & 72.3 & \\
\hline \multicolumn{7}{|l|}{ Language* $(n=509)$} \\
\hline English & 52.7 & \multirow[t]{6}{*}{$<0.001$} & 36.7 & \multirow[t]{6}{*}{0.002} & 83.4 & \multirow[t]{6}{*}{$<0.001$} \\
\hline Cantonese & 34.9 & & 19.2 & & 49.6 & \\
\hline Mandarin & 17.4 & & 16.7 & & 31.1 & \\
\hline Korean & 16.7 & & 48.4 & & 57.5 & \\
\hline Vietnamese & 24.4 & & 26.3 & & 43.9 & \\
\hline Spanish & 12.6 & & 36.1 & & 42.7 & \\
\hline \multicolumn{7}{|l|}{ Years in the U.S. $(n=338)$} \\
\hline$<1-10$ & 33.8 & \multirow[t]{3}{*}{0.39} & 5.4 & 0.04 & 39.2 & 0.55 \\
\hline $11-15$ & 24.2 & & 27.9 & & 39.0 & \\
\hline 16 or more & 20.7 & & 33.3 & & 48.0 & \\
\hline Medicare/Medicaid $(n=506)$ & 21.5 & 0.005 & 37.0 & 0.29 & 54.5 & 0.25 \\
\hline Health status $(n=506)$ & & & & & & \\
\hline Excellent/very good & 40.9 & 0.02 & 36.0 & 0.59 & 69.3 & 0.02 \\
\hline Good & 30.7 & & 30.6 & & 55.3 & \\
\hline Fair/poor & 26.4 & & 33.6 & & 54.7 & \\
\hline Chronic conditions $^{\dagger}(n=509)$ & & & & & & \\
\hline Diabetes mellitus & 33.0 & 0.63 & 37.4 & 0.12 & 62.9 & 0.15 \\
\hline Hypertension & 33.2 & 0.22 & 34.0 & 0.45 & 60.9 & 0.10 \\
\hline Dyslipidemia & 30.7 & 0.50 & 34.7 & 0.29 & 58.6 & 0.97 \\
\hline $\begin{array}{l}\text { Number of prescribed medications, }{ }^{\dagger} \text { mean } \\
\text { (SE) }(n=509)\end{array}$ & $6.8(0.34)$ & 0.006 & $6.7(0.34)$ & 0.01 & $6.7(0.26)$ & $<0.001$ \\
\hline
\end{tabular}

Notes: All percentages are weighted for age and language with inverse probability weights to account for differences in survey response.

Table reports row percentages

* survey administration language

+ abstracted from electronic medical record claims data 
Table 3 Adjusted logistic regression models for use of remote Internet refill systems by English proficiency

\begin{tabular}{|c|c|c|c|c|c|c|}
\hline \multirow[t]{2}{*}{ Characteristic } & \multicolumn{2}{|c|}{$\begin{array}{l}\text { Model } 1 \text { Use of Internet } \\
\text { refills }\end{array}$} & \multicolumn{2}{|c|}{$\begin{array}{l}\text { Model } 2 \text { Use of telephone } \\
\text { refills }\end{array}$} & \multicolumn{2}{|c|}{$\begin{array}{l}\text { Model } 3 \text { Use of Internet } \\
\text { or telephone }\end{array}$} \\
\hline & AOR & $95 \%$ CI & AOR & $95 \%$ CI & AOR & $95 \%$ CI \\
\hline \multicolumn{7}{|l|}{ Language } \\
\hline English-proficient & ref & - & ref & - & Ref. & - \\
\hline Limited English proficiency & $0.27^{*}$ & $(0.17,0.45)$ & 0.87 & $(0.52,1.47)$ & $0.18^{\ddagger}$ & $(0.11,0.31)$ \\
\hline Age & $0.97^{\dagger}$ & $(0.95,0.99)$ & $1.03^{\dagger}$ & $(1.01,1.05)$ & 1.00 & $(0.97,1.02)$ \\
\hline \multicolumn{7}{|l|}{ Gender } \\
\hline Male & ref & _ & ref & _- & ref & _ \\
\hline Female & 1.14 & $(0.75,1.76)$ & $1.78^{\dagger}$ & $(1.18,2.70)$ & $1.81^{\dagger}$ & $(1.20,2.74)$ \\
\hline \multicolumn{7}{|l|}{ Education completed } \\
\hline University/college & ref & & ref & & ref & \\
\hline Trade school & 0.78 & $(0.36,1.68)$ & 0.64 & $(0.28,1.44)$ & 0.55 & $(0.25,1.25)$ \\
\hline High school or less & $0.50^{\dagger}$ & $(0.31,0.81)$ & 1.07 & $(0.65,1.75)$ & 0.70 & $(0.44,1.12)$ \\
\hline \multicolumn{7}{|l|}{ Health status } \\
\hline Excellent/very good & ref & - & ref & - & ref & - \\
\hline Good & 0.84 & $(0.50,1.41)$ & 0.87 & $(0.52,1.46)$ & 0.81 & $(0.47,1.42)$ \\
\hline Fair/poor & 1.02 & $(0.57,1.85)$ & 1.03 & $(0.59,1.78)$ & 1.16 & $(0.65,2.07)$ \\
\hline
\end{tabular}

Notes: All models included survey weights for age and language using inverse probability weights to account for differences in survey response $A O R=$ adjusted odds ratio

Ref = reference category

$C I=95 \%$ confidence intervals

$t=p$ value $<0.01$

$f=p$ value $<0.001$

with diabetes and other chronic conditions may benefit most from the use of remote medication refills. ${ }^{16}$ Considering that many patients often do not refill their medications, providers who care for LEP and EP patients can encourage adherence by advising patients of the different medication refill options available to them. ${ }^{17}$

We extend the literature by finding that linguistically diverse patients are less likely than EP patients to use any remote medication refill system and that the lower use is driven by a lower likelihood of using the online medication refill function. Our results add to previous studies that focused on raceethnicity but not language. A strength of this study is its focus on a linguistically diverse patient population with multiple chronic conditions receiving care in an integrated group practice setting. Research has shown that minorities in general are less likely to use online health-related patient SMRs or portals, ${ }^{12-14}$ and our results suggest that speaking a non-English language is associated with low use of remote refill systems, including the Internet.

This study has limitations. We used self-reports for some measures, which are subject to recall bias and socially desirable answers. Identifying LEP individuals by interpreter use rather than self-report may lead to under-identification of the LEP population. However, identifying LEP patients by this approach would bias LEP versus EP comparisons towards the null hypothesis. Using self-report to identify LEP patients may overestimate their true English proficiency, as patients may attempt to get through a clinical encounter with limited English fluency. ${ }^{18}$ The use of interpreter measures provides an objective measure of the need for interpreter services. Although the response rate was about $35 \%$, this rate is similar to surveys of patients from a health system conducted by survey vendors in more than one language, ${ }^{19,20}$ and is higher than telephone surveys among community samples. ${ }^{21,22} \mathrm{We}$ also weighted our data to reduce bias from non-response. Our results may not be generalized to all patients with LEP or other healthcare systems, as we focused on a sample within an integrated group practice healthcare system. We did not assess whether patients had access to the Internet or whether providers encouraged the use of the SMR medication refill function, although a study in the same health system found that Internet use and/or provider encouragement did not explain lower use of patient SMR records among African American patients. ${ }^{23}$ It is possible that potential confounders not measured in this study, such as household members with English proficiency and patient health literacy, could help explain the findings. The cross-sectional design does not allow for inference of causal relationships.

The provision of linguistically appropriate health care is warranted given the growing linguistic diversity across the U.S. ${ }^{24}$ The National Standards for Culturally and Linguistically Appropriate Services in Health and Health Care (the National CLAS Standards) were recently updated, and establish a blueprint for health care organizations to implement linguistically appropriate services. ${ }^{25}$ As health systems focus more on the National CLAS Standards and follow Title VI of the Civil Rights Act to improve patient experiences with care, ${ }^{26}$ it will be important that LEP patients are also provided the convenience of an SMR with the ease of requesting refills for prescription medications. Additional studies should focus on uninsured patients and whether use of the Internet SMR features is associated with process and clinical outcomes. ${ }^{16}$ This research is critical, because health systems increasingly rely on Internet-based SMRs to expand access to services in accordance with meaningful use standards. Investments in making telephone refill systems available in common non- 
English languages would be another step in the right direction toward enhancing patient experiences with care.

In summary, we describe variation in the self-reported use of remote medication refills, particularly focusing on Internet refills, among a linguistically diverse group of patients with similar access to care. All patients in this study had hyperlipidemia, hypertension, and/or diabetes, populations at high risk for medication non-adherence. ${ }^{2}$ If our results are replicated in other studies, they would then suggest that increased emphasis on Internet refill systems may increase rather than decrease disparities by differentially improving access to refills for EP patients over those with LEP.

Acknowledgments: NIMHD grant (R01-1MD006185-01A1; PI: Leo S. Morales), NIA Paul B. Beeson Career Development Award (K23 AG042961-01; PI: Gerardo Moreno), and NIA P30-AG021684. The content does not necessarily represent the official views of the NIA or the NIH.

Conflicts of Interest: The authors declare that they do not have a conflict of interest.

Corresponding Author: Gerardo Moreno, MD, MSHS; UCLA Department of Family MedicineDavid Geffen School of Medicine at UCLA, 10880 Wilshire Blvd., Suite 1800, Los Angeles, CA 90024, USA (e-mail: gemoreno@mednet.ucla.edu).

\section{REFERENCES}

1. Ralston JD, Coleman K, Reid RJ, Handley MR, Larson EB. Patient experience should be part of meaningful-use criteria. Health Aff (Millwood). 2010;29(4):607-613.

2. Ho PM, Rumsfeld JS, Masoudi FA, et al. Effect of medication nonadherence on hospitalization and mortality among patients with diabetes mellitus. Arch Intern Med. 2006;166(17):1836-1841.

3. Osborn CY, Mayberry LS, Wallston KA, Johnson KB, Elasy TA. Understanding patient portal use: implications for medication management. J MedInt Res. 2013;15(7), e133.

4. Wilson E, Chen AH, Grumbach K, Wang F, Fernandez A. Effects of limited English proficiency and physician language on health care comprehension. J Gen Intern Med. 2005;20(9):800-806.

5. Karliner LS, Auerbach A, Napoles A, Schillinger D, Nickleach D, PerezStable EJ. Language barriers and understanding of hospital discharge instructions. Med Care. 2012;50(4):283-289.

6. Moreno G, Morales LS. Hablamos Juntos (Together We Speak): interpreters, provider communication, and satisfaction with care. J Gen Intern Med. 2010;25(12): 1282-1288.

7. Moreno G, Tarn DM, Morales LS. Impact of interpreters on the receipt of new prescription medication information among Spanish-speaking Latinos. Med Care. 2009;47(12):1201-1208.
8. Ngo-Metzger Q, Sorkin DH, Phillips RS, et al. Providing high-quality care for limited English proficient patients: the importance of language concordance and interpreter use. J Gen Intern Med. 2007;22(Suppl 2):324-330.

9. Sarkar U, Lyles CR, Parker MM, et al. Use of the refill function through an online patient portal is associated with improved adherence to statins in an integrated health system. Med Care. 2014;52(3):194-201.

10. Ancker JS, Barron Y, Rockoff ML, et al. Use of an electronic patient portal among disadvantaged populations. J Gen Intern Med. 2011;26(10):1117-1123.

11. Zenk SN, Schulz AJ, Israel BA, James SA, Bao S, Wilson ML. Neighborhood racial composition, neighborhood poverty, and the spatial accessibility of supermarkets in metropolitan Detroit. Am J Public Health. 2005;95(4):660-667

12. Roblin DW, Houston TK 2nd, Allison JJ, Joski PJ, Becker ER. Disparities in use of a personal health record in a managed care organization. J Am Med Inform Assoc. 2009;16(5):683-689.

13. Sarkar U, Karter AJ, Liu JY, et al. Social disparities in Internet patient portal use in diabetes: evidence that the digital divide extends beyond access. J Am Med Inform Assoc. 2011;18(3):318-321.

14. Yamin CK, Emani S, Williams DH, et al. The digital divide in adoption and use of a personal health record. Arch Intern Med. 2011;171(6):568-574.

15. Obesity and overweight. World Health Organization Fact sheet no. 311. 2006.

16. Harris LT, Koepsell TD, Haneuse SJ, Martin DP, Ralston JD. Glycemic control associated with secure patient-provider messaging within a shared electronic medical record: a longitudinal analysis. Diabetes Care. 2013;36(9):2726-2733.

17. Shrank WH. Helping our patients to adhere to chronic medications: a new arrow for the quiver. J Gen Intern Med. 2011;26(12):1394-1395.

18. Zun LS, Sadoun T, Downey L. English-language competency of selfdeclared English-speaking Hispanic patients using written tests of health literacy. J Natl Med Assoc. 2006;98(6):912-917.

19. Hays RD, Martino S, Brown JA, et al. Evaluation of a Care Coordination Measure for the Consumer Assessment of Healthcare Providers and Systems (CAHPS) Medicare survey. Med Care Res Rev. 2014;71(2):192202.

20. Hays RD, Berman LJ, Kanter MH, et al. Evaluating the psychometric properties of the CAHPS Patient-centered Medical Home survey. Clin Ther. 2014;36(5):689-696 e681.

21. Chawla N, Breen N, Liu B, Lee R, Kagawa-Singer M. Asian american women in california: a pooled analysis of predictors for breast and cervical cancer screening. Am J Public Health. 2015;105(2):e98-e109.

22. California Health Interview Survey. CHIS 2009 Methodology Series: Report 4 - Response Rates. Los Angeles, CA: UCLA Center for Health Policy Research; 2011.

23. Lyles CR, Harris LT, Jordan L, et al. Patient race/ethnicity and shared medical record use among diabetes patients. Med Care. 2012;50(5):434440.

24. Ryan C. Language Use in the United States: 2011, American Community Survey Reports: United States Census Bureau; 2013.

25. Koh HK, Gracia JN, Alvarez ME. Culturally and Linguistically Appropriate Services-advancing health with CLAS. N Engl J Med. 2014;371(3):198201.

26. Chen AH, Youdelman MK, Brooks J. The legal framework for language access in healthcare settings: Title VI and beyond. J Gen Intern Med. 2007;22(Suppl 2):362-367. 